\title{
DIREITO BRASILEIRO E LINGUÍSTICA APLICADA AUTORREFLEXIVA UMA PROPOSTA DE INTERCONEXÃO
}

Guilherme Lima Cardozo é doutorando em Estudos da Linguagem pela PUC-RIO.

Email: guilhermegoldenstein@gmail.com

\begin{abstract}
Resumo
Este artigo promove uma interconexão entre o discurso jurídico e a proposta de uma Linguística Aplicada autorreflexiva, através da interface entre as bases que sustentam ambos os discursos, a fim de proporcionar uma reflexão comprometida com a pluralidade e com a ética. Confrontar-se-ão o pano de fundo essencialista que rege o Direito brasileiro e a necessidade contemporânea de se compreender a linguagem como prática social, refletindo sobre si mesma, assumindo suas escolhas políticas, ideológicas e éticas.
\end{abstract}

\begin{abstract}
This article promotes an interconnection between legal discourse and the proposal of a self-reflexive Applied Linguistics, through the interface among the grounds which sustain both discourses in order to provide a reflection committed to diversity and ethics. The essencialist views that govern Brazilian Law will be confronted with the contemporary need to understand language as a social practice, reflecting on itself, assuming its political, ideological and ethical choices.
\end{abstract}

\section{1) Introdução}

Este artigo visa a promover uma interconexão entre o discurso presente no universo jurídico e a proposta de uma Linguística Aplicada (LA) autorreflexiva, acareando as bases que sustentam ambos os discursos, a fim de proporcionar uma reflexão verdadeiramente comprometida com a pluralidade, com a mobilidade de valores e com a ética, haja vista serem os assuntos aqui abordados de indiscutível impacto na práxis social. A interconexão aqui almejada colocará em confronto o pano de fundo essencialista que rege o Direito brasileiro, ainda imerso na "verdade" que habita a letra da lei, e a necessidade, imposta pelas mutações em curso no mundo contemporâneo, de se compreender a linguagem como prática social, refletindo sobre si mesma, assumindo suas escolhas políticas, ideológicas e éticas, bem como incorporando uma mestiçagem teórico-metodológica - conforme podemos observar nas pesquisas no campo de LA feitas por Branca Falabella Fabrício, Luiz Paulo da Moita Lopes, Roxane Helena Rojo, Kanavillil Rajagopalan, entre outros -, corroborando o senso de responsabilidade social em todos os campos, seja no do Direito, seja no da LA.

Para melhor compreendermos as escolhas feitas neste artigo, em algumas linhas falaremos sobre as motivações pessoais que impulsionaram a delineação do tema em questão, ratificando o que já há muito propõem diversos estudiosos de pesquisa e linguagem de diferentes campos, como Nietzsche (2000), Foucault (1979), Wittgenstein (2012), Coulthard (2004), etc.: a impossibilidade de neutralidade na pesquisa. Neutralidade essa que se imagina - e pior, acredita-se piamente - comparecer em larga escala na interpretação do texto jurídico, prática controversa às características mais eloquentes da sociedade contemporânea.

Após esse breve introito, buscaremos possíveis causas históricas que, porventura, tenham legado ao Direito brasileiro essa visão representacionista e essencialista de linguagem, através das quais é sempre possível alcançar uma "verdade", e, assim, proceder a um julgamento perfeito, sem máculas e contaminações subjetivas. Para isso, ser-nos-á auxílio a literatura de Gershom Sholem (2009) sobre o Direito hebraico, bem 
como as comparações entre o Direito romano e a formação do jurista brasileiro feitas por Salerno e Zemuner (2006). Logo após, para melhor entender como se fará essa interconexão entre o Direito brasileiro e os pressupostos da LA, cuidaremos de apontar neste trabalho o que vem a ser a Linguística Aplicada, do que se ocupa, com que se preocupa - para tanto, priorizaremos as noções de Moita Lopes (2006) e Davies (1999) -, e como essas reflexões podem atuar diretamente no discurso jurídico, aqui problematizado. Abordaremos também o que já vem sendo feito no campo da Linguística Forense, mormente por Malcolm Coulthard (2004), e de que forma são aplicadas as preocupações da LA no campo do texto jurídico, quais os seus resultados, se possui reconhecimento social e se, portanto, faz os operadores do direito refletirem acerca da linguagem como prática social.

Por fim, após revisitarmos os conceitos supramencionados e termos compreendido basicamente em que eixo epistemológico cada um dos objetos de estudos deste trabalho - Direito e LA - se encontram, observaremos ao longo da pesquisa se: a) há falta de comprometimento das instituições com os indivíduos e se o Direito cumpre a sua função socializadora no mundo contemporâneo; b) os operadores do Direito adquiriram um regime de percepção tão multifocais e fragmentários, como exige a atual compreensão de espaço-tempo; c) a mestiçagem do discurso aparece em ações do Direito para as minorias; d) o quanto a lei fisicaliza o "eu” jurídico; e) os operadores são mantenedores ou desconstrutores do modelo essencialista presente no Direito brasileiro.

Esperamos que, ao fim deste artigo, o ideal a que nos propusemos seja devidamente alcançado: o de oferecer reflexão contínua sobre as práticas sociais dentro do discurso jurídico, não abrindo mão de teorias e metodologias, mas aliando os pressupostos de uma Linguística Aplicada Indisciplinar - usando os termos de Moita Lopes - visando a uma aplicação discursiva social e eticamente comprometida com a comunidade em geral.

\section{2) Motivação pessoal}

No momento em que escrevi este artigo ainda fazia parte do corpo de funcionários do Tribunal de Justiça deste estado, e, particularmente, o que me motivou a escrever sobre o tema - apesar de estar enfadado da prática e do discurso jurídicos - foi exatamente a falta de vontade escrever sobre ele. Para me fazer melhor entender, dentro do universo jurídico existem os chamados operadores do direito, os quais se dividem em advogados, defensores, promotores, juízes e desembargadores,os membros da administração do Judiciário - onde me encontro - e os usuários do direito - a sociedade como um todo. Da mesma forma que há uma divisão funcional entre operadores e usuários, acredita-se haver também uma divisão de poder: o desembargador e o juiz, por estarem acima do escrivão e do escrevente na hierarquia judiciária, da mesma forma buscam repisar uma hierarquia científica e linguística; grande parte da sociedade que se vale do Direito para buscar seus direitos, acaba ratificando esse vão devido à falta de acesso ao conhecimento específico; no contexto de audiência, onde se encontram usuários e operadores do direito, há clara inclinação em se ratificarem as diferenças, primordialmente por meio da linguagem. No intuito de escancarar essa falta de boa 
vontade ética que enumerarei alguns casos em que o vão linguístico se fez presente, objetivando a legitimação de um afastamento entre operadores e usuários.

\section{1) O caso "Dona Diva"}

Não é incomum que, após a realização de audiências perante o juiz e o promotor, mesmo que acompanhadas por advogado/defensor público, muitos usuários se dirijam ao cartório - local onde o escrivão e os escreventes (membros da Administração Judiciária) trabalham - para exigir explicações sobre o ocorrido na audiência. Lembrando que esses profissionais a quem os usuários vêm recorrer não participam do evento, apenas os operadores do direito e as pessoas envolvidas.

Confesso que não são todos os funcionários da Justiça que se dispensam o tempo de "traduzir" os termos da assentada do juiz para o "português popular" dos usuários, e nem sempre aqueles que o fazem algumas vezes querem fazê-lo sempre. No entanto, há uma figura emblemática em minha comarca chamada Dona Diva, a qual depois de toda audiência, seja com o juiz, seja com conciliador, seja por não ter entendido o que o defensor público lhe disse numa consulta de processo, vem pedir a mim esclarecimentos sobre o seu caso. Entre as chorosas reclamações dessa senhora, elenquei algumas importantes para discussão: a) "Eles não me deixam falar..."; b) "O que que significa essa palavra aqui?”, c) “É tudo muito confuso, eu só quero receber meu dinheiro...”; d) "Meu filho, muito obrigada de novo, né?!".

Foucault em Microfísica do Poder afirma que nossas práticas discursivas ordenam o mundo social, produzindo domínios de saber, dentro do qual uma "trama epistemológica" se articula, revitalizando conceitos, fortalecendo definições e estabelecendo padrões do que é normal e do que é desviante: tudo isso concorre para a formação de relações de força nos diversos campos do saber, evocando visões de verdade, usadas de forma a controlar e regular as práticas sociais, essa é a noção de regimes de verdade foucaultianos (FOUCAULT, 1979, p. 144).

Quanto a isso, Fabrício afirma que

Tais campos, os regimes de verdade focaultianos, produzem a ideia de poder, pois normatizam e normalizam a vida social, legitimando conceitos, crenças, valores e possibilidades de ser, agir e desejar. Nessa abordagem, os sentidos seriam interessados, pois são produzidos por uma trama de forças e condições sócio-historicamente determinadas (FABRICIO, 2006, p. 55)

Portanto, há um sério problema de apropriação da "verdade" por parte dos operadores do direito em relação à Dona Diva, a qual não consegue sequer entender o que está acontecendo naqueles "aqui e agora" (GOFFMAN, 1974) no que diz respeito à sua interação com os membros do Judiciário. Daí ser mister "não nos eximir do cuidado com os efeitos de nossas construções para o mundo social" (FREIRE COSTA apud FABRÍCIO, 2006, p. 55).

\section{2) O caso "Gilson Noé"}

Branca Falabella Fabrício sublinha alguns fenômenos marcantes no mundo globalizado, os quais devem ser observados pelos pesquisadores de linguagem e 
sociedade, entre eles a mestiçagem de discursos e práticas tradicionalmente pertencentes a domínios discretos e o surgimento de novos roteiros de subjetividade/identidade (FABRÍCIO, 2006, p. 47).

Outro caso instigante enfrentado por mim foi o de retificação de registro de nascimento do senhor Gilson Noé, o qual, após uma cirurgia, assumiu sua identidade feminina, e buscava apenas o referendo da justiça. Um dos questionamentos que fizemos no penúltimo parágrafo foi se o Direito brasileiro (logo, a máquina que o faz funcionar: o poder judiciário) acompanha a cultura "trans" em que vivemos, a qual exige uma percepção instantânea e fragmentária dos acontecimentos sociais. $\mathrm{O}$ caso "Gilson Noé" demonstrou que não: o aprisionamento da lei a um conceito de "verdade", que ainda permanece no que concerne à sexualidade, ainda não contempla casos em que um homem se torne mulher, logo, a linguagem jurídica e a prática social não estão em comunhão efetiva e a preocupação com o outro é menos importante que a manutenção de uma "verdade". Nietzsche brilhantemente já descortinava esse ideário hipócrita a que muitos almejam:

(...) fixa-se aquilo que doravante deverá ser "verdade", ou seja, inventa-se uma designação uniformemente válida e obrigatória para as coisas, e a legislação da linguagem estabelece também as primeiras leis da verdade: assim se origina, pela primeira vez, o contraste entre verdade e falsidade (NIETZSCHE, 2000, p. 176).

E ainda que

as verdades são ilusões, das quais se esqueceram que o são, metáforas que se tornaram gastas e sem força sensível, moedas que perderam sua efígie e agora só entram em consideração como metal, não mais como moedas (NIETZSCHE, 1995, p.48).

É palmar, após essas citações, entendermos que o Direito brasileiro ainda nada nas águas da metafísica da presença, aquela que se ancora na possibilidade real de encontrar um sentido estático nas coisas e, assim, manipulá-las em seu benefício. Trazendo a LA autorreflexiva como contraponto, desejamos que "a crença de que desvendar para o leigo as operações ideológicas e de poder "ocultas" em certas práticas discursivas [seja] o caminho para libertá-lo de estruturas sociais opressivas" (FABRÍCIO, 2006, p. 50).

\section{3) Origem do direito essencialista}

O Direito brasileiro tal como é hoje decorre substancialmente do chamado Nouus Iustinianus Codex, ou outras palavras, do Direito Romano. Este, obviamente, sofreu diversas reformulações que resultaram no Direito Romano-Helênico, o qual criou institutos adotados até hoje por muitos códigos, inclusive o nosso. Dentre eles, o pátrio poder, o regime de bens, o divórcio, o concubinato, a tutela, o direito de herança e muito sobre os contratos (SALERNO \& ZEMUNER, 2006, p. 128-129). Entretanto, apesar de alguns estudiosos afirmarem ser o Direito Romano influenciado pelos etruscos, desenha-se a este pesquisador muito provável a possibilidade de que, após contatos 
intensos com os hebreus durante muitos anos, os romanos tenham capturado a essência do regime legal hebraico.

O apego à letra, característico dos hebreus, é ratificado por alguns estudos cabalísticos acerca da natureza da Torah (livro de leis sagrado dos judeus) como não somente composta por nomes de Deus, mas como o grande nome de Deus, de forma que a Lei em si representava a essência divina comunicada a nós. Scholem afirma que "dizer que a Torah é um nome não significa que este seja um nome que possa ser pronunciado como tal" (SCHOLEM, 2009, p. 52), sendo assim conservado o aspecto de inefabilidade e de imutabilidade das verdades divinas. Os judeus mais ortodoxos ligados à Halachá (conjunto de leis da religião judaica) e menos às questões místicas, como os cabalísticos, acreditavam no significado estritamente literal das letras da lei. Para eles a Torah não contém uma única letra ou ponto sequer supérfluos, pois é um "edifício" talhado a partir do Nome de Deus, e que, diferentemente de um organismo vivo com partes vitais e outras nem tanto, toda a Torá é igualmente preponderante para o funcionamento do conjunto. Segundo essa teoria, não haveria a mínima distinção entre, por exemplo, a seção que trata do levantamento do censo de Israel, onde Moisés elencará as gerações dos filhos de Jacó, e os dez mandamentos da Sagrada Torah, onde estão a base jurídica, moral e religiosa da tradição judaica (SCHOLEM, 2009, p. 66). Para eles, a Torah é a materialização do corpo de Deus, daquilo que o homem pode conhecer de Deus, dessa forma, a Lei é detentora de toda a verdade, e quem não se alia a essa verdade, é considerado desviante.

Pode parecer algo místico, fanático, todavia deixemos de lado o aspecto religioso de tal empresa e reflitamos sobre as conveniências da Torah e do Direito brasileiro: a) o intérprete da Torah - o levita - era um homem sagrado, somente ele poderia fornecer as verdades ali presentes. Segundo Coulthard, advogados e membros do Tribunal se veem como guardiões dos significados legais; b) na Torah habita "a verdade", procedente do próprio Deus. Portanto, não se lhe admitem interpretações humanas e contextuais. Apesar de cheio de lacunas, o Direito brasileiro abarca todas as situações de maneira genérica, evitando individualizações de casos. Assim, acredita-se chegar numa neutralidade; c) A Torah determina o comportamento do homem bom. $\mathrm{O}$ Direito brasileiro, ao contrário do consuetudinário (baseado nos costumes da comunidade) prescreve o que são direitos do cidadão, e o que são condutas desviantes, reflexo de considerável inobservância das mutáveis práticas sociais.

Em ambos os casos podemos perceber sinuosas tendências essencialistas, confluentes no intuito de frear os anseios inerentes ao espírito humano, renegando o que muitos filósofos já proclamaram acerca da realidade: ela está sempre em movimento, sendo a verdade um acordo entre os homens, e não algo essencial (cf. Nietzsche, Foucault, Wittgenstein, etc.).

Um estudioso da linguagem jurídica, Samene Santana, resume bem o que dissemos acima:

A linguagem do sistema judiciário nacional chega a confundir-se em alguns pontos com a linguagem das religiões. O caráter esotérico de ambas as linguagens também as aproxima no sentido de que supostamente tratam de um saber restrito a iniciados que 
não pode ou não deve ser vulgarizado. Particularmente dentre os ocidentais, muitos sinais (signos) religiosos migraram para a liturgia forense sem qualquer dificuldade, mesmo que a separação dos poderes temporal e religioso seja aclamada como uma das maiores conquistas da democracia moderna. São frequentes os ícones entre ambas as instituições: balanças e espadas empunhadas por estátuas de feições angelicais são versões profanas dos arquétipos de virtude das divindades greco-romanas. O significante em ambas também coincide: a crença na igualdade dos homens e num sentimento de Justiça acima deles. A Justiça impõe o signo da divindade para realçar seu poder (SANTANA, p. 03)

\section{4) O que é Linguística Aplicada?}

Para compor essa seção não fui em busca de definições para o que seja LA, mas de subsídios que fornecessem material suficiente para uma interconexão entre o que se propõe nos estudos de LA e o que eles podem influenciar em uma possível autorreflexividade do Direito brasileiro.

Inicialmente, observa-se no primeiro capítulo de An Introduction to Applied Linguistics, de Alan Davies, a própria escolha do título e a não casualidade das aspas (Historyand 'definitions'), pois, conforme o autor reafirma no início do texto: “(...) applied linguistics must be defined through demonstration, that is by giving examples of its work. One reason for this is that providing a definition of applied linguistics is difficult" (DAVIES, 1999, p. 01).

Deixadas de lado as tentativas de definição e mais focado nas tarefas da LA, Davies traz os pontos de vista de Widdowson e Rampton, os quais sugerem ser o trabalho da LA não uma propriedade de linguistas, mas, se vista por um ângulo de transdisciplinariedade, os pesquisadores de LA podem ser formados por gente de outros campos:

This extreme view (Widdowson, 1980) suggests that applied linguistics does not belong with any exclusivity to linguists. The practitioners of applied linguistics, according to this view, are drawn from a wider pool (Rampton, 1997) (...) Here, applied linguistics are really still linguists who happen to be involved in applications, which they may label as applied linguistics. However, their knowledge and skill are insufficient for those applications. They need the cooperation of other professional in relevant fields (...) (ibidem, p. 02).

Moita Lopes fornece um entendimento sobre o que possa ser a LA, resumidamente:

(...) a LA é entendida aqui como uma área de investigação aplicada, mediadora, interdisciplinar, centrada na resolução de problemas de uso da linguagem, que tem um foco na linguagem de natureza processual, que colabora com o avanço do conhecimento teórico, e que utiliza métodos de investigação de natureza positivista e interpretativista (MOITA LOPES, 1996, p. 22-23).

Contudo o autor salienta anteriormente que há um crescente interesse pela pesquisa de base interpretativista, focada no processo de uso da linguagem, atrelada à noção de que falar uma língua é uma prática social ou uma forma de vida, o que nos remete imediatamente a um dos filósofos da linguagem mais incisivos na crítica ao essencialismo, Wittgeinstein: "os significados não estão em algum ponto fixo e 
transcendental do universo, prontos a serem capturados e aplicados invariavelmente, eles estão no uso dentro do jogo social" (WITTGENSTEIN, 2012, § 43).

Feitas essas considerações acerca do que seria o trabalho da LA, na próximaseção elencaremos onde exatamente esses pressupostos atuariam efetivamente em pontos nevrálgicos e lacunosos do Direito brasileiro, visando a responder às perguntas colocadas na parte inicial deste artigo.

\section{5) LA: exercício de autorreflexividade ao Direito brasileiro}

A título de recordação, trago novamente ao corpo do texto as questão que buscaremos responder ao longo desta seção, mesmo que algumas delas já tenhamos mencionado anteriormente. Nosso objetivo aqui é responder se no discurso jurídico: a) há falta de comprometimento das instituições com os indivíduos e se o Direito cumpre a sua função socializadora no mundo contemporâneo; b) os operadores do Direito adquiriram um regime de percepção tão multifocais e fragmentários, como exige a atual compreensão de espaço-tempo; c) a mestiçagem do discurso aparece em ações do Direito para as minorias; d) o quanto a lei fisicaliza o "eu" jurídico; e) os operadores são mantenedores ou desconstrutores do modelo essencialista presente no Direito brasileiro.

Para responder a primeira questão, trago à tona os estudos de Malcolm Coulthard sobre Linguística Forense, uma área ainda pouco explorada no Brasil, mas que traz um enriquecimento enorme para a área jurídica, pois o linguista desenha sua atuação neste cenário como uma espécie de perito. Como área dos estudos discursivos que atua no "mundo real", a Linguística Forense lida exatamente com as desigualdades existentes entre as grandes corporações/instituições e os usuários do direito (COULTHARD, 1996). Segundo Coulthard, nos últimos quinze anos houve uma utilização crescente dos linguistas em casos onde houvesse disputa sobre algum aspecto de texto escrito, como por exemplo os plágios, morfemas "apropriados" por grandes marcas, ambiguidades léxico-gramaticais em textos jurídicos, etc.

Coulthard enumera alguns casos onde o linguista atua como perito, observando-se que sua função é, além de fornecer um guia semântico aos operadores do direito (SOLAN apud COULTHARD, 1996), mais precisamente, subsídios para que se chegue a uma conclusão sobre a disputa no campo linguístico, preponderantemente atua na tentativa de igualar os desiguais, seja entre uma grande empresa e uma pequena, seja entre o próprio poder público e um leigo, seja entre instituições e o particular. Há alguns casos enumerados pelo autor onde o linguista como perito atuou na defesa do uso do morfema "Mc" pela empresa Quality, ao criar uma cadeia de hotéis chamada McSleep. A empresa fora acusada de se apropriar de um elemento mórfico já pertencente à rede de alimentícios McDonalds (COULTHARD, 1996, p. 161). O trabalho do linguista neste caso foi levantar dois argumentos linguísticos que ajudassem na causa: a frequência do uso deste prefixo, quando não associado àMcDonalds, significando "básico, conveniente, barato e estandardizado", bem como sua natureza patronímica, em especial na Escócia e na Irlanda, significando "filho de" (ibidem, p. 162).

Outro caso interessante onde o linguista, dessa vez, atuou como igualador de forças entre o poder público e o particular foi na mudança de uma sentença, a qual, por 
equívoco de interpretação de leitura, aplicou cinco anos de prisão ao réu, quando o correto seria uma sentença de menos de dois anos de prisão. Neste caso a corte suprema não só acatou o argumento linguístico de Kaplan et al, como também o citou em seu julgamento (ibidem, 164).

O último dos casos que vamos contemplar, a fim de corroborar a visão de que a Linguística Forense trabalha na defesa dos desiguais social, linguística e juridicamente, é um de significados pragmáticos em uma proposta de seguro, caso este muito comum no Brasil. Em um questionário básico feito pela empresa, o cliente respondeu "not" à pergunta: "Have you any impairments? [...] Loss of sight or hearing? [...] Loss of arm or leg? [...] Are you clippled or deformed? [...] If so explain... (ibidem, 166), pelo que não recebeu o seguro que devia, pois, segundo alegações da empresa, mentiu ao responder o questionário, visto que era obeso, tinha colesterol alto, ocasionalmente, dores nas costas. O argumento da linguista (Prince) em defesa do cliente foi o de que qualquer leitor cooperativo teria inferido que a palavra "impairments" estava sendo usada naquele contexto particular para significar uma condição física relativamente severa e incapacitante, pois "impairments" não tinha sido definida no documento da empresa de outra forma, e os exemplos, além de não fornecerem grande auxílio, poderiam ainda ser tratados como enganosos (ibid.). O juiz neste caso julgou a favor do cliente.

Para responder à segunda pergunta elencada no início da seção, o exemplo relatado na seção 2.2 funciona como um retrato de como a máquina do Judiciário ainda não se inclinou a, conforme Fabrício, "pensar, operando em uma dimensão ética, nos possíveis efeitos e consequências do caminho percorrido pelo [operador do direito] pesquisador, interrogando-[se] a quem eles podem atingir/beneficiar/prejudicar, e de que forma" (FABRÍCIO, 2006, p. 60).

O terceiro tópico encontra coro nas palavras de Samene Santana, em seu trabalho sobre a linguagem jurídica como obstáculo ao acesso à justiça. Ele afirma que

A linguagem jurídica especificou-se para segregar. Segregar conhecimento, o acesso à justiça, bem como ao judiciário, o "modo de vida" dos indivíduos, as relações interpessoais e assim, definir-se como forma de dominação. A linguagem simples, fora das convenções arcaicas de manutenção do poder, seria a independência real do Poder Judiciário, todavia, engessa-se o Direito sob o conceito de ciência exata como se assim fossem as relações sociais (SANTANA, p.04)

Vemos na afirmação de Santana que a linguagem jurídica - minha experiência também o diz, e isso já vimos aqui na seção "o caso Dona Diva" - usa de palavras de difícil compreensão e termos jurídicos exclusivos, distanciando-se do que hoje é tão necessário: a mestiçagem do discurso e de práticas, a fim de atingir o alvo do discurso jurídico, a sociedade. Fabrício, baseada nos pensamentos de Wittgenstein (2000), Foucault (1979) e Nietzsche (2000), afirma que os campos devem se interrogar "acerca da relevância social da temática e do objetivo gerais de nossos estudos, tendo em vista os atores sociais que vivenciam as práticas envolvidas no fenômeno a ser focalizado" (FABRÍCIO, 2006, p. 59), portanto, "mapear a rede semântica e a episteme em jogo, necessariamente sustentadas por uma multiplicidade de vozes, sistemas de valoração, discursos e regimes de verdade" (ibid.). 
Esse terceiro ponto nos faz chegar a uma conclusão no ponto subsequente: a transparência dos atos públicos, apesar de ser um princípio democrático e arrebatado pela Constituição Federal, não comparece no discurso jurídico. Em seu texto há um acentuado uso de arcaísmos, brocardos latinos e termos jurídicos, mostrando a especificidade lexical dentro dessa comunidade e seu alto teor de conservadorismo linguístico. Segundo Bezerra, 1998; Cornu, 2000; Damião, 2000; Bittar, 2001, o fato de a legalidade dos textos jurídicos ser diretamente condicionada à escrita faz com que a formalidade ganhe espaço e, de certa maneira, mantenha a hierarquização da comunidade e afaste a linguagem jurídica da ordinária. Na visão dos operadores do direito, petições, sentenças, recursos, acórdãos, são especificamente direcionados a operadores do direito - como se não tratassem todos esses documentos da vida de indivíduos.

Dessa forma, visualizamos a necessidade, de que falou Santana, de uma afirmação de poder da comunidade jurídica em relação aos usuários do direito, contribuindo para a fiscalização do "eu" jurídico, ou seja, por meio de um gênero discursivo próprio, materializa-se na sociedade uma vertente do conhecimento a que somente os guardiões dos significados legais têm acesso. Constrói-se, assim, uma verdade essencial e inalcançável pelos "estrangeiros", deixando-se de lado as preocupações sociais e éticas, as quais deveriam nortear o horizonte do Direito brasileiro.

Por fim, chegamos a uma triste e lamentável conclusão de que os operadores do direito, através de suas práticas discursivas, lutam pela manutenção desse modelo essencialista que vige na prática jurídica, conforme Santana coloca:

O poder segregado está engajado no Direito que "manda e desmanda" e a linguagem cheia de rebuscamentos desnecessários é base para a manutenção deste direito que se explica por suas normas e não pelas transformações sociais (SANTANA, p. 14).

Dentre alguns aspectos enumerados por Moita Lopes, os quais devem constituir a LA, talvez o que melhor se aplica a uma Linguística Aplicada ao campo do Direito brasileiro seja a da LA como área de mestiçagem, dialogando com o mundo contemporâneo, explodindo a relação teoria e prática - Derrida diria que o ideal seria implodir uma na outra.E, ainda, redescrevendo o sujeito social, compreendendo-o como heterogêneo, fragmentado e fluido e, mais importante, a LA como "área em que ética e poder são pilares cruciais (...) uma vez que não é possível relativizar todos os significados: há limites éticos que devem nos orientar" (MOITA LOPES, 2006, p. 31).

Encerrando a discussão sobre o aspecto essencialista da justiça, trago à guisa palavras de Michel Foucault:

O funcionamento arcaico da justiça se inverte: parece que remotamente a justiça tinha sido um direito para os que estavam sob sua jurisdição (direito de pedir justiça, se concordavam com isso) e um dever para os árbitros (obrigação de demonstrar o seu prestígio, a sua autoridade, a sua sabedoria, o seu poder político-religioso); daí em diante vai-se tornar um direito (lucrativo) para o poder, obrigação (custosa) para os subordinados (FOUCAULT, 1979, p. 25). 


\section{6) Considerações finais}

As linhas desenvolvidas neste artigo ratificam o que serviu de introito à pesquisa: o direito brasileiro e suas práticas caminham na contramão das linhas filosóficas mais críticas do discurso. Enquanto estas apregoam uma interconexão maior entre as diversas disciplinas, entre sujeito e objeto, entre teoria e prática, aqueles ainda insistem na manutenção de métodos ultrapassados e incongruentes com as mudanças pelas quais a sociedade em geral vem passando há décadas.

Ao passo que me sinto tentado a desenvolver esse tipo de pesquisa, não me comprazo em tratar do tema, pois vejo como muito infeliz essa distância entre os estudos linguísticos indisciplinares, conforme Moita Lopes afirma, e a prática discursiva dentro dos ambientes jurídicos no Brasil, especialmente aqui no Rio de Janeiro. Certa feita, em conversa com colegas de mestrado e doutorado na PUC-Rio, diante da Professora Doutora Inês Miller, quando perguntado sobre a importância dos estudos pós-modernos de linguagem na esfera jurídica, afirmei que, contraditoriamente, o Direito lida, através da linguagem, com a vida das pessoas. Por que então a recusa em lidar com a linguagem como forma de vida? Deixemos essa pergunta reverberar na mente dos próximos pesquisadores dessa área, ainda pouco explorada, mas com um território vastíssimo para checagem e investigação. Nossa intenção é que este pequeno compêndio possa trazer alguma colaboração para esse âmbito de pesquisa linguística dentro do judiciário, e incentivar essa prática autorreflexiva em outros setores engessados da esfera pública ou particular de nosso país.

\section{7) Referências bibliográficas}

COULTHARD, M. Linguistas como peritos/as. Tradução Carmem Rosa CaldasCoulthard. In: Linguagem em (Dis)curso - LemD, Tubarão, v.4, n. esp., p. 159-176, 2004

DAVIES, A. Anintroductiontoappliedlinguistics. Frompracticetotheory. Edinburgh: Edinburgh University Press, 1999.

FABRICIO, B.F. Linguística aplicada como espaço de "desaprendizagem": Redescrições em curso. In: MOITA LOPES, L.P. (Org.), Por uma linguística aplicada indisciplinar, São Paulo: Parábola Editora, 2006, pp.45-65.

FOUCAULT, M. Microfísica do Poder. Rio de Janeiro: Graal, 1979.

GOFFMAN, E. Frame analysis. New York: Harper \&Row, 1974.

MOITA LOPES, L.P. Uma linguística aplicada mestiça e ideológica: interrogando o campo como linguista aplicado.In: MOITA LOPES, L.P. (Org.), Por uma linguística aplicada indisciplinar, São Paulo: Parábola Editora, 2006, pp.13-44. 
Oficina de linguística aplicada. Campinas: Mercado de Letras, 1996.

NIETZSCHE, F. Sobre a verdade e a mentira no sentido extra-moral (1873) in Obras Incompletas, São Paulo: Editora Nova Cultura, 2000.

SALERNO, M. \& ZEMUNER, A.F. A importância do Direito Romano na formação do jurista brasileiro. In: Semina: Ciências Sociais e Humanas, Londrina, v. 27, n., p. 125133, jul./dez. 2006.

SANTANA, S.B.P. A linguagem jurídica como obstáculo ao acesso à justiça. Uma análise sobre o que é o Direito engajado na dialética social e a consequente desrazão de utilizar a linguagem jurídica como barreira entre a sociedade e o Direito/Justiça. Monografia apresentada para obtenção de grau em Direito. [s.l.]

SHOLEM, Gershom. A Cabala e seu simbolismo. Trad. Hans Borger e J. Guinsburg. São Paulo. Perspectiva, 2009

WITTGENSTEIN, L. Investigações filosóficas. Trad. Marcos G. Montagnoli. $7^{\mathrm{a}}$ Edição, Ed. Vozes, Petrópolis, 2012. 